4. Gong Z, Bai S, Hu S. Mixed phenotype blast phase of chronic myeloid leukemia in the era of tyrosine kinase inhibitor therapy. Blood J 2016;128:5438.

5. Neuendorff NR, Burmeister T, Dörken B, Westermann J. BCR-ABL-positive acute myeloid leukemia: a new entity? Analysis of clinical and molecular features. Ann Hematol 2016;95:1211-1221.

6. Millot $F$, Baruchel A, Guilhot J, Petit A, Leblanc T, Bertrand $Y$, Mazingue $F$, Lutz $P$, Vérité $C$, Berthou $C$, Galambrun C, Bernard F, Yacouben $K$, Bordigoni P, Edan C, Reguerre Y, Couillault G, Méchinaud F, Cayuela JM, Guilhot F.
Imatinib is effective in children with previously untreated CML in early chronic phase: results of the French national phase IV trial. J Clin Oncol 2011;29:2827-2832.

7. de la Fuente J, Baruchel A, Biondi A, de Bont E, Dresse MF, Suttorp M, Millot F; International BFM Group (iBFM) Study Group Chronic Myeloid Leukaemia Committee. Managing children with chronic myeloid leukaemia (CML): recommendations for the management of CML in children and young people up to the age of 18 years. Br J Haematol 2014;167:33-47.

๑Copyright 2019 by Turkish Society of Hematology

Turkish Journal of Hematology, Published by Galenos Publishing House

\title{
Myeloid Sarcoma of the Parotid Gland and Stomach Presenting with Obstructive Jaundice: A Rare Presentation
}

\section{Obstrüktif Sarılık ile Başvuran Parotis Bezi ve Midenin Myeloid Sarkoması: Nadir Bir Sunum}

(D) Sugeeth M. Thambi1 ${ }^{1}$, (D Sreejith G. Nair ${ }^{1}$, (D) Rony Benson¹, (D) Jayasudha A. Vasudevan², (D) Rekha A. Nair²

1 Regional Cancer Centre, Department of Medical Oncology, Thiruvananthapuram, India

${ }^{2}$ Regional Cancer Centre, Department of Pathology, Thiruvananthapuram, India

To the Editor,

Myeloid sarcoma (MS) is the extramedullary deposit of immature myeloid cells and disrupts the normal tissue architecture [1]. MS commonly occurs in the skin, central nervous system, eyes, and testes. Gastrointestinal involvement is common $[2,3]$. Here we present a case of isolated MS of the parotid and stomach presenting with jaundice.

A 55-year-old male was evaluated with swelling of the right parotid gland for two months. Fine-needle aspiration was suggestive of a parotid neoplasm and the patient underwent a right-sided total parotidectomy. Post-op histopathological examination was suggestive of non-Hodgkin's lymphoma. While the patient was recovering, he developed jaundice. Liver function tests showed bilirubin of $5.3 \mathrm{mg} / \mathrm{dL}$ (direct: $4.2 \mathrm{mg} / \mathrm{dL}$ ). Contrast-enhanced computed tomography of the neck, chest, and abdomen was performed, which showed irregular soft tissue thickening in the parotid bed along with an enlarged enhancing left level IB nodal area $(21 \times 12 \mathrm{~mm})$. The abdomen showed intrahepatic biliary radicle dilatation with a soft tissue nodule at the porta. There was also soft tissue thickening involving the cardia and lesser curvature of the stomach along with multiple enlarged perigastric nodes (Figure 1).

Peripheral smear and bone marrow studies were normal. Review of the parotidectomy specimen showed a neoplasm composed of atypical medium to large cells. Tumor cells were myeloperoxidase-positive, CD33-positive, CD43 focalpositive, and CD68-negative and were compatible with MS (Figure 2). During work-up bilirubin increased to $20 \mathrm{mg} / \mathrm{dL}$ and the patient underwent percutaneous transhepatic biliary drainage. Upper gastrointestinal endoscopy was suggestive of mucosal irregularity involving the cardia and lesser curvature of the stomach. Endoscopic guided biopsy from the lesion was suggestive of MS. The patient's bilirubin normalized after stenting.

The patient was scheduled for $7+3$ induction ( 7 days of cytarabine at $100 \mathrm{mg} / \mathrm{m}^{2}$ as a 24-hour infusion along with 3 days of daunorubicin at $60 \mathrm{mg} / \mathrm{m}^{2}$ ). Post-induction reevaluation was done and contrast-enhanced computed tomography showed no significant lymph nodes, with significant reduction in the gastric and duodenal wall thickening along with resolution of the intrahepatic biliary radicle dilatation. The patient was scheduled for consolidation with high-dose cytarabine and received 3 cycles. He remained on follow-up after the completion of 3 cycles.

Isolated MS usually does not produce any specific symptoms besides the local symptoms of the organ involved. Local imaging is usually warranted in the form of computed tomography or magnetic resonance imaging [4]. Bone marrow study is also warranted to confirm isolated MS as 

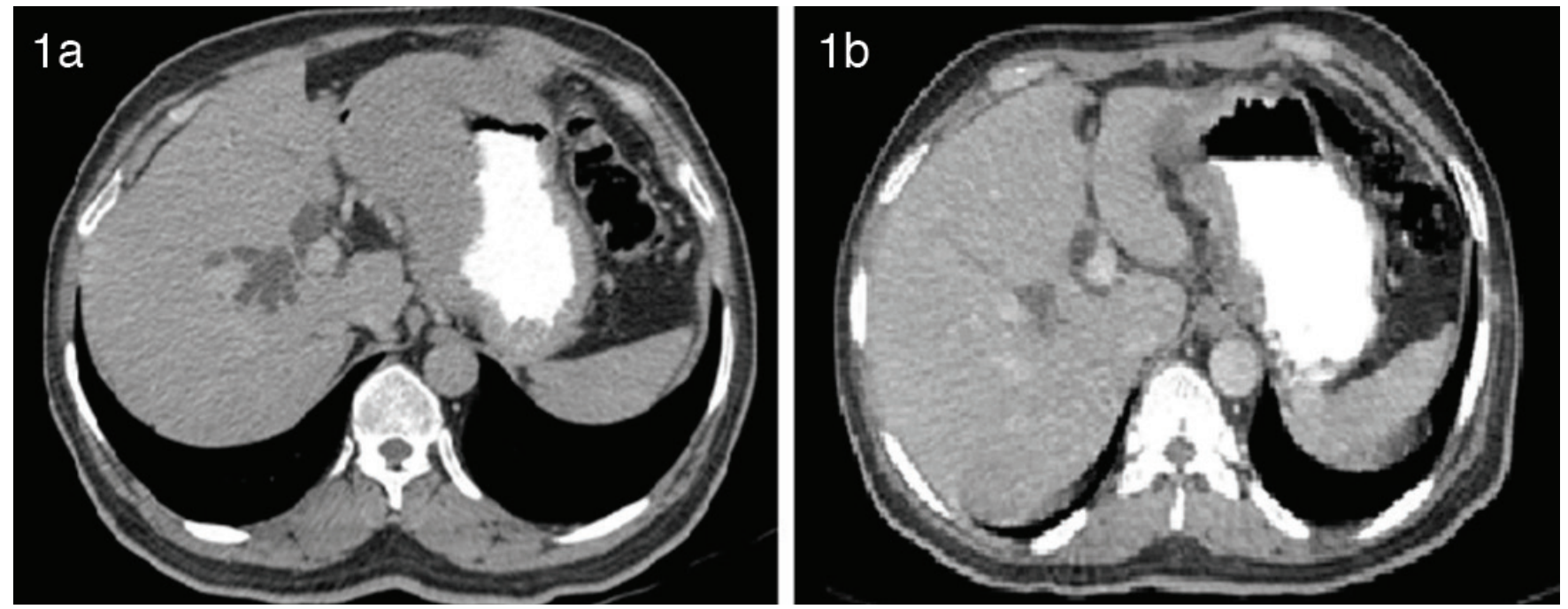

Figure 1. Contrast-enhanced computed tomography of the neck, chest, and abdomen showing intrahepatic biliary radicle dilatation and stomach wall thickening involving the cardia and lesser curvature of the stomach (a) and post-induction scan showing significant reduction in the stomach wall thickening and resolution of intrahepatic biliary radicle dilatation (b).
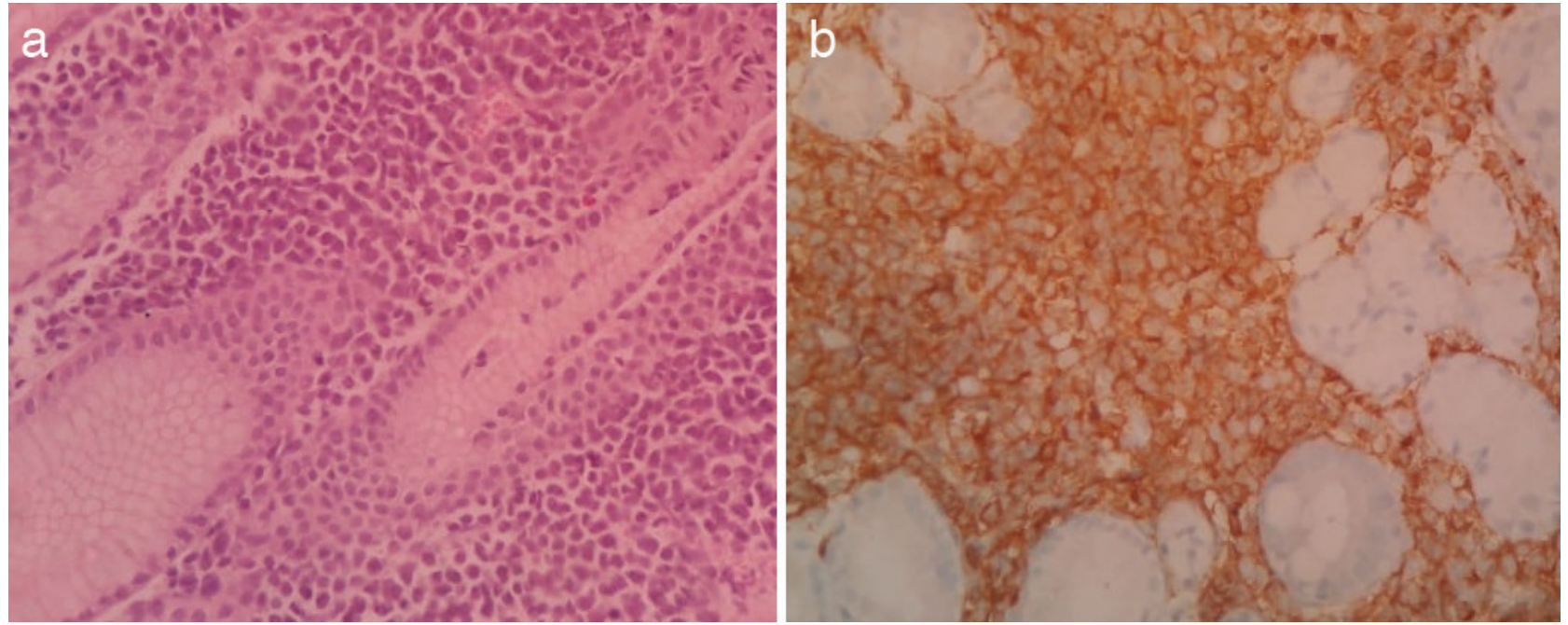

Figure 2. (a) Hematoxylin and eosin results showing medium to large atypical cells with scanty cytoplasm and irregular nuclear membranes; (b) tumor cells positive for myeloperoxidase.

most cases occur in patients with AML. Systemic therapy is warranted in such cases where patients receive induction chemotherapy similar to AML, as in our case [5]. The 5-year survival in patients with MS is about 20\% and the use of chemotherapy has been associated with better survival [6]. There are reports that malignant cells in chloroma may evade immune surveillance and thus have a higher chance of survival. Another contributing factor to immune escape is the partial loss of several human leukocyte antigen class I genes [7].

Keywords: Myeloid sarcoma, Parotid gland, Stomach

Anahtar Sözcükler: Myeloid sarkoma, Parotis bezi, Mide

Informed Consent: Received.
Conflict of Interest: The authors of this paper have no conflicts of interest, including specific financial interests, relationships, and/or affiliations relevant to the subject matter or materials included.

\section{References}

1. Campidelli C, Agostinelli C, Stitson R, Pileri SA. Myeloid sarcoma: extramedullary manifestation of myeloid disorders. Am J Clin Pathol 2009;132:426-437.

2. Vachhani P, Bose P. Isolated gastric myeloid sarcoma: a case report and review of the literature. Case Rep Hematol 2014;2014:541807.

3. Derenzini E, Paolini S, Martinelli G, Campidelli C, Grazi GL, Calabrese C, Zinzani PL, Baccarani M. Extramedullary myeloid tumour of the stomach and duodenum presenting without acute myeloblastic leukemia: a diagnostic and therapeutic challenge. Leuk Lymphoma 2008;491:159-162.

4. Bakst RL, Tallman MS, Douer D, Yahalom J. How I treat extramedullary acute myeloid leukemia. Blood 2011;118:3785-3793. 
5. Yamauchi $\mathrm{K}$, Yasuda M. Comparison in treatments of nonleukemic granulocytic sarcoma: report of two cases and a review of 72 cases in the literature. Cancer 2002;94:1739-1746.

6. Lan TY, Lin DT, Tien HF, Yang RS, Chen CY, Wu K. Prognostic factors of treatment outcomes in patients with granulocytic sarcoma. Acta Haematol $2009 ; 122: 238-246$.
7. Johansen $S$, Kollsete Gjelberg $H$, Ahmed $A B$, Bruserud $\emptyset$, Reikvam $H$. Myeloid sarcoma after allogenic stem cell transplantation for acute myeloid leukemia: successful consolidation treatment approaches in two patients. Case Rep Oncol Med 2018;2018:7697283.

oCopyright 2019 by Turkish Society of Hematology

Turkish Journal of Hematology, Published by Galenos Publishing House

\title{
An Unusual Presentation of Hairy Cell Leukemia
}

\section{Tüylü Hücreli Löseminin Alışılmadık Prezantasyonu}

\author{
(D) Smeeta Gajendra1, (D Bhawna Jha1, (D) Sarita Prasad1, (D) Pratibha Dhiman², (D) Manorama Bhargava1 \\ ${ }^{1}$ Medanta - The Medicity, Departments of Pathology and Laboratory Medicine, Gurgaon, India \\ 2 Medanta - The Medicity, Department of Medical Oncology and Hematology, Gurgaon, India
}

\section{To the Editor,}

The aberrant expression of CD5 in both hairy cell leukemia $(\mathrm{HCL})$ and $\mathrm{HCL}$-variant (HCL-v) is very rare; only 26 such cases have been reported in the literature [1]. Simultaneous absence of splenomegaly and cytopenia(s) is even rarer, which may pose a diagnostic dilemma. We describe a case of CD5-positive $\mathrm{HCL}$ with absence of splenomegaly and cytopenia. To the best of our knowledge, only one case of HCL without cytopenia and splenomegaly has been reported in the literature to date [2], but without CD5 positivity. Our patient was a 59-year-male, who presented with intermittent cough with expectoration for the last 3 to 4 years with no history of fever. Radiological investigations including $\mathrm{X}$-ray and computed tomography scans were normal. Complete blood counts showed hemoglobin of $15.1 \mathrm{~g} / \mathrm{dL}$, white blood cell count of $7.73 \times 109 / \mathrm{L}$ (neutrophils: 52\%, lymphocytes: $45 \%$, monocytes: $2 \%$, and platelet count of 153×109/L. Peripheral blood smear (PBS) and bone marrow aspirate (BMA) showed 10\% and 24\% abnormal lymphoid cells, respectively (Figure 1A). These cells were small to medium in size, with abundant pale blue cytoplasm and circumferential hairy projections. Bone marrow biopsy showed interstitial aggregates of abnormal lymphoid cells (Figure 1B), which were positive for CD20 and annexin 1. Flow cytometric immunophenotyping (Figure $1 \mathrm{C}$ ) revealed these cells to be positive for CD19, CD20, CD22, CD103, CD11c, CD123, CD25, CD5 (heterogeneous), CD200, CD23 (dim), and kappa and negative for CD10 and FMC7. The patient was found to be positive for BRAF V600E mutation. A diagnosis of $\mathrm{HCL}$ with aberrant CD5 was made.
$\mathrm{HCL}$ is an indolent small mature B lymphoid malignancy accounting for $2 \%$ of lymphoid leukemias [3]. The three most important findings for diagnosis are splenomegaly, cytopenia(s), and bone marrow dry tap resulting from marrow fibrosis [4]. In unsuspected cases with unusual presentation, the best approach for diagnosis is the careful examination of morphological details on PBS and BMA to identify the morphological features of hairy cells, which are further confirmed upon characteristic immunophenotypic profiles, as in our case. Differential diagnoses of HCL include chronic lymphocytic leukemia, prolymphocytic leukemia, splenic marginal zone lymphoma, HCL-v, and mantle cell lymphoma, which can be excluded based on characteristic morphological and immunophenotypic features. Hairy cells are 10-15 $\mu \mathrm{m}$ in diameter, with central or eccentric round, oval, or indented nuclei; reticular or netlike chromatin pattern; indistinct or absent nucleoli; pale blue cytoplasm with fine, hair-like projections or ruffled borders; and positive staining for tartrate-resistant acid phosphatase [5]. A typical combination of immunophenotypic markers expressed by hairy cells such as CD19, CD22, and CD79b, with brighter expression of CD20, along with co-expression of CD103, CD123, CD25, and CD11C, confirms the diagnosis [6].

In conclusion, this case posed a diagnostic challenge as the patient had no cytopenias or splenomegaly along with CD5 positivity. This case is important because it creates awareness of this uncommon presentation of $\mathrm{HCL}$ and emphasizes that the best approach in diagnosing $\mathrm{HCL}$ is to give careful attention to morphological details while interpreting peripheral blood, as in our case, which can prompt detailed evaluation of bone marrow 